\title{
Calibration of YSZ Oxygen Sensor for Use in a Lead-alloy Coolant System
}

\author{
S.H. Lee, ${ }^{1, *}$ C.H. Cho, ${ }^{1}$ T.Y. Song, ${ }^{1}$ I.S. Hwang ${ }^{2}$ \\ ${ }^{1}$ Korea Atomic Energy Research Institute, Daejeon 305-600, Korea \\ ${ }^{2}$ Seoul National University, San 56-1, Shinlim-dong, Gwanak-ku, Seoul 151-742, Korea
}

Received 8 September 2008; accepted 14 November 2008

\begin{abstract}
Liquid lead-bismuth eutectic (LBE) may see extensive use as a coolant fluid, and perhaps also as a spallation target, in the next generation nuclear energy system. However, it is very corrosive to the common steels used in nuclear installations. This corrosion problem can be prevented by the formation of a protective oxide layer on the exposed surface of steel. For this purpose, accurately measuring and controlling the oxygen concentration in liquid LBE is very important. Electrochemical oxygen sensors with $\mathrm{In} / \mathrm{In}_{2} \mathrm{O}_{3}$ and $\mathrm{Bi} / \mathrm{Bi}_{2} \mathrm{O}_{3}$ reference systems can be used as in situ devices for measuring the oxygen concentration in liquid LBE. YSZ (Yttria Stabilized Zirconia) oxygen sensor with molten bismuth saturated with oxygen as a reference, has been selected to measure the oxygen concentration in LBE coolant system. The oxygen concentration difference across the solid electrolyte and the resultant oxygen ion conduction inside the electrolyte establish an electromagnetic force (EMF) that is used to measure the ppb level of dissolved oxygen concentration in liquid LBE. In this paper, the sensitivity of an YSZ oxygen sensor has been evaluated. Sensor calibration curves in liquid $\mathrm{LBE}$ at $450{ }^{\circ} \mathrm{C}$ have been obtained.
\end{abstract}

Keywords: YZS sensor, calibration, oxygen content measurement, liquid LBE, EMF.

\section{Introduction}

Lead and LBE has been a primary candidate material for high-power spallation neutron target and coolant in accelerator driven systems (ADS) and coolant in advanced nuclear reactors due to its favourable thermal-physical and chemical properties, such as a low melting point, low vapour pressure, wide margin to boiling, and chemical inertness resulting in mild reaction with air and water $[1,2]$. However, LBE is very corrosive to the common steels used in nuclear

\footnotetext{
* Corresponding author. E-mail address: shlee6@kaeri.re.kr
} 
installations due to the high solubility of the major alloying components of steel. Such long term corrosion problem can be prevented by producing and maintaining a protective oxide layer on the exposed surface of stainless steel. For this purpose, it is required to accurately control the concentration of oxygen dissolved in liquid LBE. Since the oxygen chemistry is sufficiently well known, protective oxide layer on the interface between LBE and steel, generally, is applied by controlling oxygen activity and concentration in liquid LBE. The stainless steel test tube contains soluble metals, such as $\mathrm{Fe}, \mathrm{Ni}$ and $\mathrm{Zr}$, which may be protected by an oxide layer, provided that the layer can be maintained by a optimal concentration of oxygen in the LBE. When a protective layer of oxide can be maintained on the surface of stainless steel pipe exposed to liquid LBE, the corrosion resistance of piping can be greatly enhanced [3]. Therefore, it is of critical importance to accurately measure and control the oxygen concentration in LBE. Oxygen concentration can be measured using the following methods: gas chromatography, fibre optic fluorosensor, or electro-chemical measurements $[4,5]$. Of these methods, those most widely used are electro-chemical ones, such as the solid state potentiometric methods. Oxygen sensor units based on YSZ solid electrolytes are currently being used for applications of liquid metals like LBE to measure oxygen concentration [6]. In this study, YSZ oxygen sensors, based on an existing automotive oxygen sensor, with molten bismuth saturated with oxygen as the reference have been selected for oxygen concentration measurement in liquid LBE. The characteristics and operation principles of YSZ oxygen sensors are discussed. And, calibration tests of YSZ oxygen sensor in liquid LBE at $450{ }^{\circ} \mathrm{C}$ were also conducted for a oxygen measurement in a leadalloy coolant system.

\section{Theoretical consideration of YSZ oxygen sensor}

\section{Solid electrolyte materials and working mechanism}

The measurement of relative oxygen concentration in liquid metals using solid electrolyte membranes is well established [7,8]. Solid electrolytes are materials which are permeable to specific ions. When zirconia, $\mathrm{ZrO}_{2}$, material is doped with $8 \sim 18 \%$ yttria, $\mathrm{Y}_{2} \mathrm{O}_{3}$, the resultant solid electrolytes material is usually called YSZ (Yttria Stabilized Zirconia), which exhibits a high oxygen mobility at over $350{ }^{\circ} \mathrm{C}[3]$. In the case of a sintered ceramic zirconia, $\mathrm{ZrO}_{2}, \mathrm{O}^{2-}$ ions may pass through the solid from high concentration side to low concentration side if they have a sufficient thermal energy. Hence, the material can be used as an electrolyte to specifically transport oxygen ions from an electrode to another electrode in an electrochemical cell. The electrochemical cell of YSZ is readily available in the form of powder or sintered closed end tubes. 


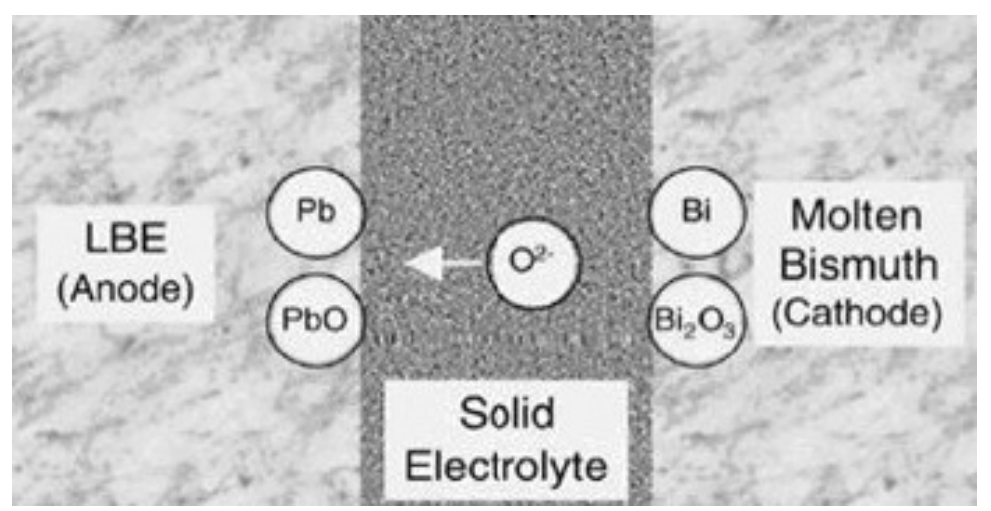

Figure 1. Scheme of the electrochemical cell in one type of solid electrolyte oxygen sensor.

During the process of electrolysis (charge transfer), oxygen molecules are converted to ions at one surface, travel through the YSZ and reformed into a neutral molecule depositing the electrons at the other surface. Thus during this process, electrons are transported from one electrode to another resulting in charge difference between the two electrodes [6]. This process is shown in Fig. 1. A metallic connection is used to source and sink electrons, and chemically catalyzing the reaction shown below.

$$
\mathrm{O}^{2}+4 \mathrm{e}^{-} \leftrightarrow 2 \mathrm{O}^{2-}
$$

In liquid metals, a certain amount of the dissolved oxygen exists as ions. Due to the oxygen concentration difference between oxygen-saturated bismuth reference and liquid metal, there exists a chemical potential difference resulting in the flow of oxygen ions (from a high to a low concentration), and accumulating charges. When it finally reaches an equilibrium, there is an EMF (electromagnetic force) across the YSZ. Oxygen concentration in liquid LBE can be determined by the EMF reading of the YSZ sensor.

\section{Reference of the oxygen sensor}

In electrochemical terms, the oxygen sensor can be represented by the following equation:

$$
\mathrm{P}_{\mathrm{O} 2} \text { or } \mathrm{a}_{0} / / \text { solid electrolyte // } \mathrm{O}, \mathrm{PbO} \text { (liquid metal) }
$$

where superscript prime denotes the reference, and the solid electrolyte is typically YSZ. For fixing the oxygen activity or partial pressure of the reference, pure oxygen $\left(\mathrm{P}^{\prime}{ }_{\mathrm{O} 2}=1\right)$ or air $\left(\mathrm{P}^{\prime}{ }_{\mathrm{O} 2}=0.21\right.$, the standard state is pure $\mathrm{O}_{2}$ at 1 atmosphere) as gas reference or metal/metal oxide buffers such as $\mathrm{Bi} / \mathrm{Bi}_{2} \mathrm{O}_{3}$, $\mathrm{Sn} / \mathrm{SnO}_{2}$ and $\mathrm{In} / \mathrm{In}_{2} \mathrm{O}_{3}$, and many other so-called coexistent electrodes of these types have been used worldwide [9]. In this study, $\mathrm{Bi} / \mathrm{Bi}_{2} \mathrm{O}_{3}$ was selected as the reference medium

If $\mathrm{Bi}$ is in equilibrium with chunks of its solid oxide, the dissolved oxygen in the liquid $\left(\mathrm{Bi}\right.$ and $\mathrm{Bi}_{2} \mathrm{O}_{3}$ ) will have a known saturation value, depending on the temperature. This saturation value will serve as a good reference [3-4]. 


\section{Signal output and oxygen concentration measurement}

The oxygen concentration difference across the solid electrolyte and the resultant oxygen ion conduction inside the electrolyte establish an EMF that can be measured to indicate the oxygen concentrations. For a YSZ sensor with $\mathrm{Bi} / \mathrm{Bi}_{2} \mathrm{O}_{3}$ as a reference electrode, and a system of liquid LBE of a unknown oxygen concentration as the counter electrode, the equation involving oxygen transport can be expressed as [3],

$$
P b+\frac{1}{3} B i_{2} O_{3(B i)} \Leftrightarrow P b O_{(P b)}+\frac{2}{3} B i
$$

During this process, oxygen is transported from the region of a high concentration $\left(\mathrm{Bi} / \mathrm{Bi}_{2} \mathrm{O}_{3}\right)$ to a low concentration side $(\mathrm{PbO})$.

According to the Nernst equation [3,5], the potential difference across the electrolyte is

$$
\begin{aligned}
E & =E_{P b O}^{0}-E_{B i_{2} O_{3}}^{0}-\frac{R T}{2 F} \operatorname{In} \frac{a_{B i}^{2 / 3} a_{P b O}}{a_{P b} a_{B i_{2} O_{3}}^{1 / 3}} \\
& =\frac{1 / 3 \Delta F_{B i_{2} O_{3}}^{0}-\Delta F_{P b O}^{0}}{2 F}-\frac{R T}{2 F} \operatorname{In} a_{P b O} .
\end{aligned}
$$

where $\mathrm{F}$ and $\mathrm{R}$ are Faraday and ideal gas constants, respectively $(\mathrm{R}=8.3114$ $\mathrm{J} / \mathrm{mol} \mathrm{K}$ and $\mathrm{F}=96487 \mathrm{C} / \mathrm{mol}$ ). Using the Oxide Handbook data [10],

$$
\log a_{P b O}=\frac{-10083}{T}(E-0.1381)-0.366
$$

Since we are interested in the Oxygen Thermodynamic Activity (OTA, a) in LBE, we can convert the experimentally obtained sensor output voltage E to OTA. OTA in LBE is another convenient parameter to calculate the oxygen concentration. The oxygen concentration in liquid LBE is simply related to OTA through the following equation as [3].

$$
\log a_{O}=\log c_{O}-\log c_{S, O}=\log c_{O}-1.2+\frac{3400}{T}
$$

The solubility of oxygen in LBE can be expressed as [3]:

$$
\log C_{S, 0}=1.2-\frac{3400}{T}
$$

The oxygen activity (a) is assumed to be simply related with the corresponding oxygen concentration by Henry's law. The value of $\log \mathrm{a}_{\mathrm{PbO}}$ equals that of $\log \mathrm{a}_{\mathrm{O}}$ because it means the oxygen content is the same as the $\mathrm{PbO}$ (in LBE) phase before solid $\mathrm{PbO}$ phase appears. Therefore, from the EMF reading of the oxygen sensor, the oxygen concentration dissolved in liquid LBE can be determined. 

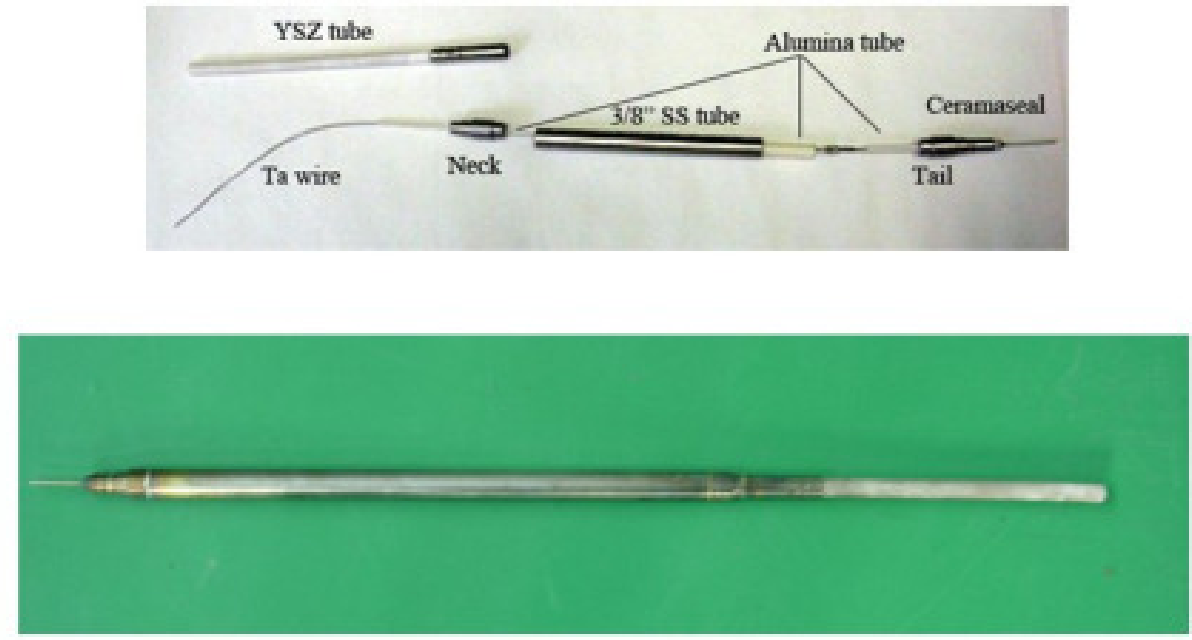

Figure 2. Photography of YSZ oxygen sensor.

\section{Experimental}

YSZ oxygen sensors used in our experiments were manufactured at Nuclear Material Lab. of Seoul National University in Korea. As shown in Fig. 2, the conical material with a rounded end is the sensing element of the oxygen sensor which is made of Yttria Stabilized Zirconia. $\mathrm{Bi} / \mathrm{Bi}_{2} \mathrm{O}_{3}$ was selected as the reference reaction and Ta wire was used to transmit the signal generated by electromotive force. All the metal pieces were assembled by an electron beam welding.

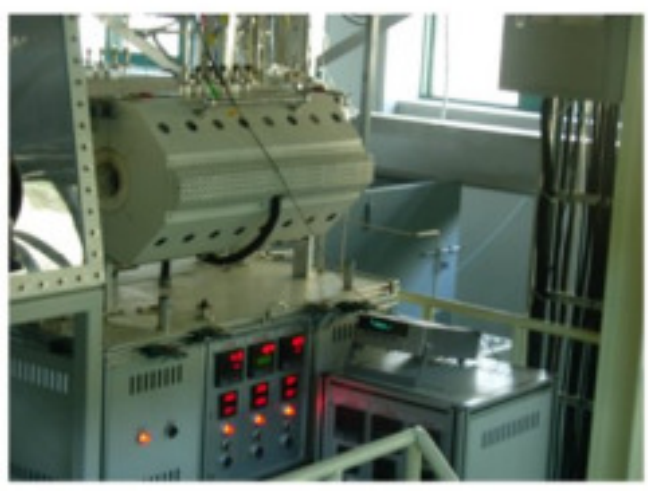

(a)

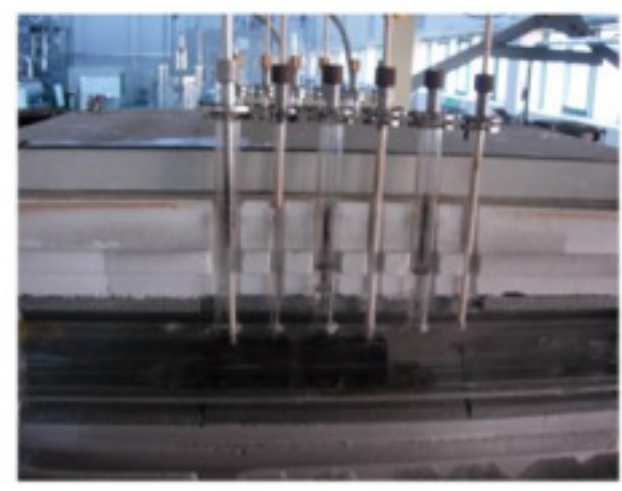

(b)

Figure 3. Experimental apparatus for the oxygen sensor calibration.

Fig. 3 shows the experimental apparatus for the oxygen sensor calibration. It is mainly composed of tube furnaces, a gas control system and a glove box. The furnace discharges all the parts of the experiment, and places the specimen in $\mathrm{Pb}$ $\mathrm{Bi}$, which has a PID controller of a 3 Zone Type. A high impedance electrometer (Keithley 6514 Electrometer) and a PC based data acquisition software 
(LabVIEW) were used to obtain the data. The cylindrical type quartz tube is tightly sealed from the outside atmosphere. A YSZ oxygen sensor, a feedthrough for a working electrode (Ta wire) and a thermocouple are installed on the top openings of the experimental apparatus, as shown in Fig. 3 (b).

The low concentration of oxygen in LBE is of the order of tens of ppb, making it nearly impossible to directly supply oxygen to its desired level. In this study, as a better alternative method, the $\mathrm{H}_{2}$ and $\mathrm{H}_{2} \mathrm{O}$ vapor ratio $\left(\mathrm{H}_{2} / \mathrm{H}_{2} \mathrm{O}\right)$ adjusting method was used to control the oxygen concentration in liquid LBE for this study. This oxygen control method has been currently used to regulate a very low level oxygen concentration [3]. Equations (5) and (6) are used to calculate the corresponding oxygen partial pressure $\left(\mathrm{Po}_{2}\right)$ for the required oxygen concentration in liquid LBE, then, equation (7) is used to determine the pressure ratio of $\mathrm{H}_{2}$ and $\mathrm{H}_{2} \mathrm{O}$ [3,11]. The $\mathrm{H}_{2} \mathrm{O}$ pressure is set at $15.94 \mathrm{mbr}$. Ar gas is forced to flow at the rate of $100 \mathrm{~cm}^{3} / \mathrm{sec}$ and the corresponding rate of the Ar-5\% $\mathrm{H}_{2}$ gas is also forced at a rate of $5 \mathrm{cc} / \mathrm{min}$ rate.

$$
\begin{gathered}
a_{0}=\frac{C_{0}}{C_{S, O}}=\left(\frac{P_{O_{2}}}{P_{O_{2}}^{*}}\right)^{1 / 2} \quad \log P_{O_{2}}^{*}=10.55-\frac{23060}{T} \\
\log P_{O_{2}}=2 \log C_{0}+8.16-\frac{16261}{T} \\
P_{O_{2}}=\frac{P_{H_{2} O}^{2}}{P_{H_{2}}^{2}} \exp \left(\frac{2 \Delta G_{H_{2} O}}{R T}\right)
\end{gathered}
$$

where $\mathrm{C}_{0}$ is oxygen concentration (wt $\left.\%\right), \mathrm{C}_{\mathrm{S}, \mathrm{O}}$ is solubility of oxygen in $\mathrm{Pb}-\mathrm{Bi}$, $\mathrm{P}^{*} \mathrm{O} 2$ is partial pressure of gas phase in equilibrium with the oxygen saturated metallic solution (atm), and $\mathrm{T}$ is temperature $(\mathrm{K})$.

Calibration of YSZ oxygen sensor was conducted by controlling the oxygen concentration from an initial condition to a minimum oxygen concentration, and then back to a maximum oxygen saturated condition in LBE at $450{ }^{\circ} \mathrm{C}$. Oxygen concentration dissolved in liquid LBE can be determined from the EMF reading of YSZ sensor by the Nernst equation. A computer based data acquisition software (LabVIEW) is utilized to continuously record the sensor signal voltage output.

\section{Results and discussion}

Before sensor calibration tests, sensitivity tests of an YSZ oxygen sensor were performed in liquid $\mathrm{LBE}$ at $450{ }^{\circ} \mathrm{C}$ for evaluating whether the sensor response is sensitive or not according to a change of the oxygen content. The oxygen concentration was controlled from an initial condition to a minimum concentration and then back to maximum concentration $\left(3.14 \times 10^{-4} \mathrm{wt} \%\right)$ by adjusting the $\mathrm{H}_{2}$ and $\mathrm{H}_{2} \mathrm{O}$ vapor ratio.

As shown in sensitivity curve of Fig. 4, signal voltage response of the oxygen sensor was very sensitive to the change of oxygen concentration, because it 
decreased or increased quickly when the oxygen concentration was changed. Thus, this YSZ oxygen sensor has adequate sensitivity.

Fig. 5 shows the sensor voltage response vs. time curve obtained from an initial oxygen condition to an allowable minimum oxygen condition in liquid LBE at $450{ }^{\circ} \mathrm{C}$. As shown in the calibration test result, we can not observe a good calibration result with $\mathrm{Fe} / \mathrm{Fe}_{3} \mathrm{O}_{4}$ equilibrium plateau corresponding to a minimum allowable oxygen concentration at which steel corrosion takes place. According to equations (2) and (3) $[3,10]$, the maximum sensor voltage of YSZ sensor at $\mathrm{Fe} / \mathrm{Fe}_{3} \mathrm{O}_{4}$ equilibrium line is about $-0.49 \mathrm{~V}$, the oxygen concentration in LBE is about $1.71 \times 10^{-9} \mathrm{wt} \%$. However, the measured sensor voltages response are changed from $-0.405 \mathrm{~V}$ to $-0.451 \mathrm{~V}$. More experiments for the $\mathrm{Fe} / \mathrm{Fe}_{3} \mathrm{O}_{4}$ equilibrium plateau are needed.

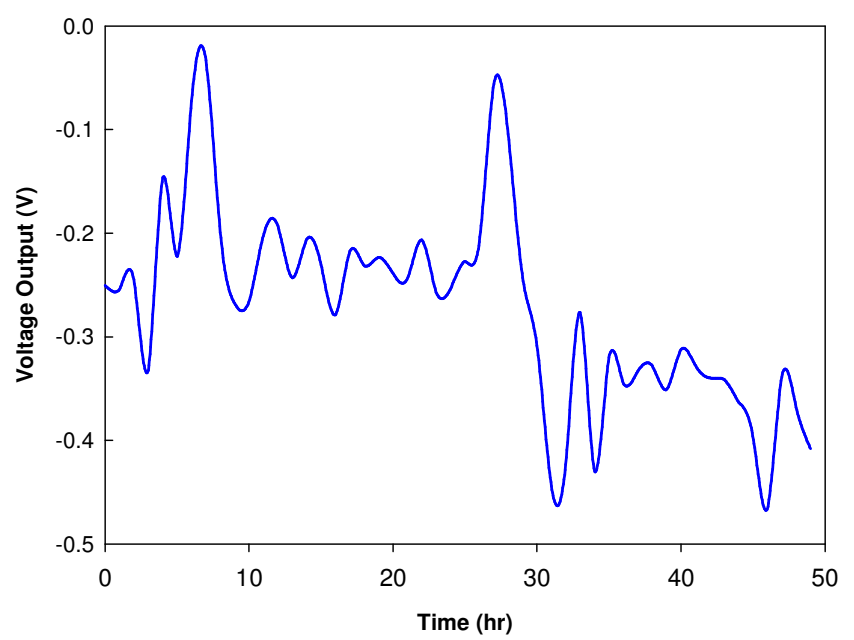

Figure 4. Sensitivity curve of an YSZ oxygen sensor to oxygen concentration change in liquid LBE at $450{ }^{\circ} \mathrm{C}$.

Fig. 6 shows the sensor voltage response vs. time curve obtained from an allowable minimum oxygen condition to a maximum oxygen saturated condition in liquid $\mathrm{LBE}$ at $450{ }^{\circ} \mathrm{C}$. The $\mathrm{Pb} / \mathrm{PbO}$ equilibrium line for the $\mathrm{PbO}$ formation was marked as a red-colored dashed line at the oxygen saturation condition in liquid $\mathrm{LBE}$ at $450{ }^{\circ} \mathrm{C}$. According to equations (2), (3) and (4), the maximum oxygen solubility in $\mathrm{LBE}$ at $450{ }^{\circ} \mathrm{C}$ is about $3.14 \times 10^{-4} \mathrm{wt} \%$, and theoretical sensor voltage at oxygen saturation condition is $-0.112 \mathrm{~V}$. As shown in the calibration test results, we observed the $\mathrm{Pb} / \mathrm{PbO}$ equilibrium plateau around $-0.1114 \mathrm{~V}$. It seems that the theoretical values $(-0.112 \mathrm{~V})$ we calculated via the Nernst equation are close. Thus, the $\mathrm{Pb} / \mathrm{PbO}$ equilibrium plateau where lead oxide starts to precipitate may be reached at a maximum oxygen saturation condition, but not entirely accurate. In this calibration test, the initial sensor voltage measured at a minimum oxygen concentration was $-0.4075 \mathrm{~V}$ and the final signal voltage at a maximum oxygen saturation condition was $-0.1114 \mathrm{~V}$.

Fig. 7 shows the whole sensor signal voltage history of an YSZ oxygen sensor obtained from an initial condition to a minimum oxygen concentration, and then back to a maximum oxygen saturated condition in liquid LBE at $450{ }^{\circ} \mathrm{C}$. As shown in the calibration test result, the values of the sensor output voltage show 
the expected patterns according to the oxygen partial pressure in the gas. The output voltage response clearly shows that the values of sensor output voltage increased and decreased gradually with an addition and removal of the oxygen concentration by adjusting the hydrogen and water vapor mixtures ratio $\left(\mathrm{H}_{2} / \mathrm{H}_{2} \mathrm{O}\right)$. We estimated the oxygen concentration from the measured partial pressure of oxygen at two plateau positions where the oxygen contents were below the saturation condition. Then, theoretically expected signal voltages at minimum and saturation oxygen conditions were also compared with the real signal. In Fig. 6 , position $<1>$ shows initial condition for oxygen sensor calibration test, position $<2>$ shows sensor voltage response at an allowable minimum oxygen condition, and position $<3>$ shows $\mathrm{Pb} / \mathrm{PbO}$ equilibrium plateau at a maximum oxygen saturation condition, respectively.

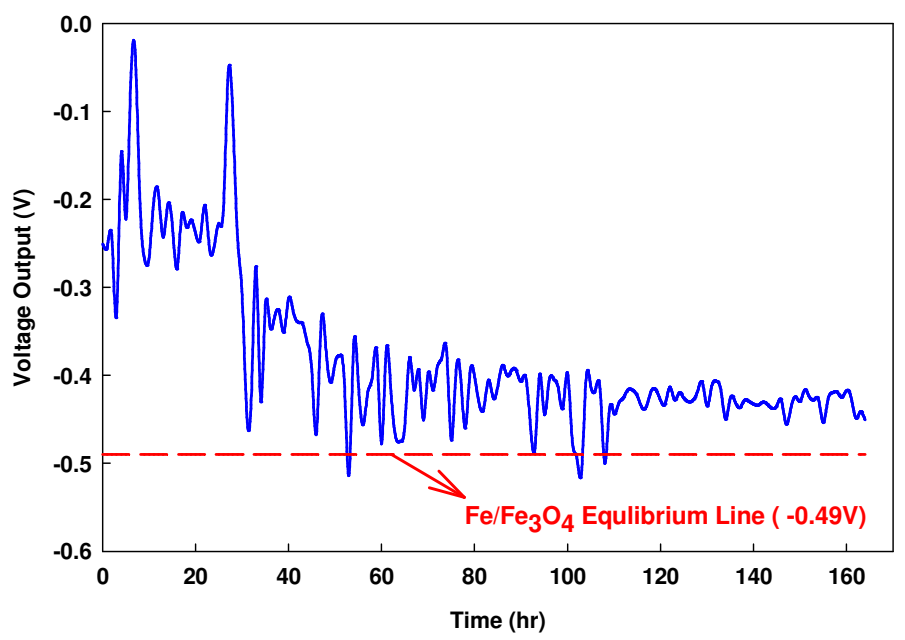

Figure 5. Sensor voltage response vs. time curve obtained from an initial condition to an allowable minimum oxygen condition in liquid LBE at $450{ }^{\circ} \mathrm{C}$.

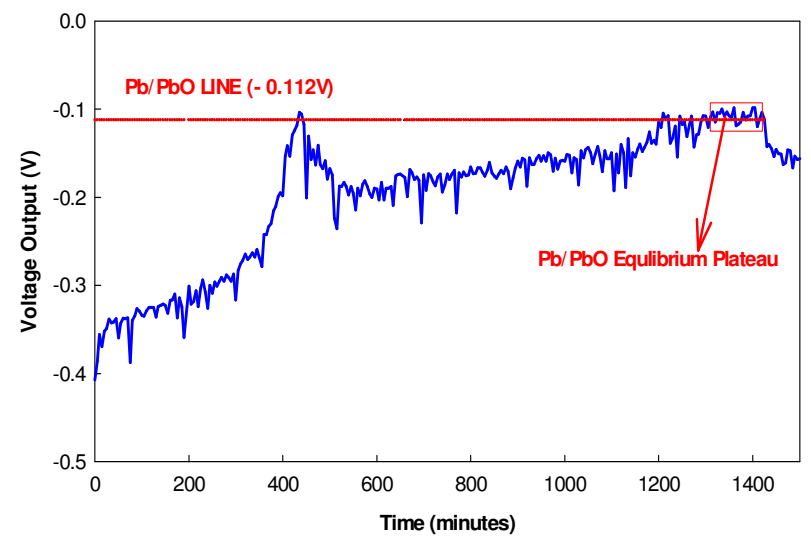

Figure 6. Sensor voltage response vs. time curve obtained from an allowable minimum oxygen condition to a maximum saturation condition in liquid $\mathrm{LBE}$ at $450{ }^{\circ} \mathrm{C}$. 


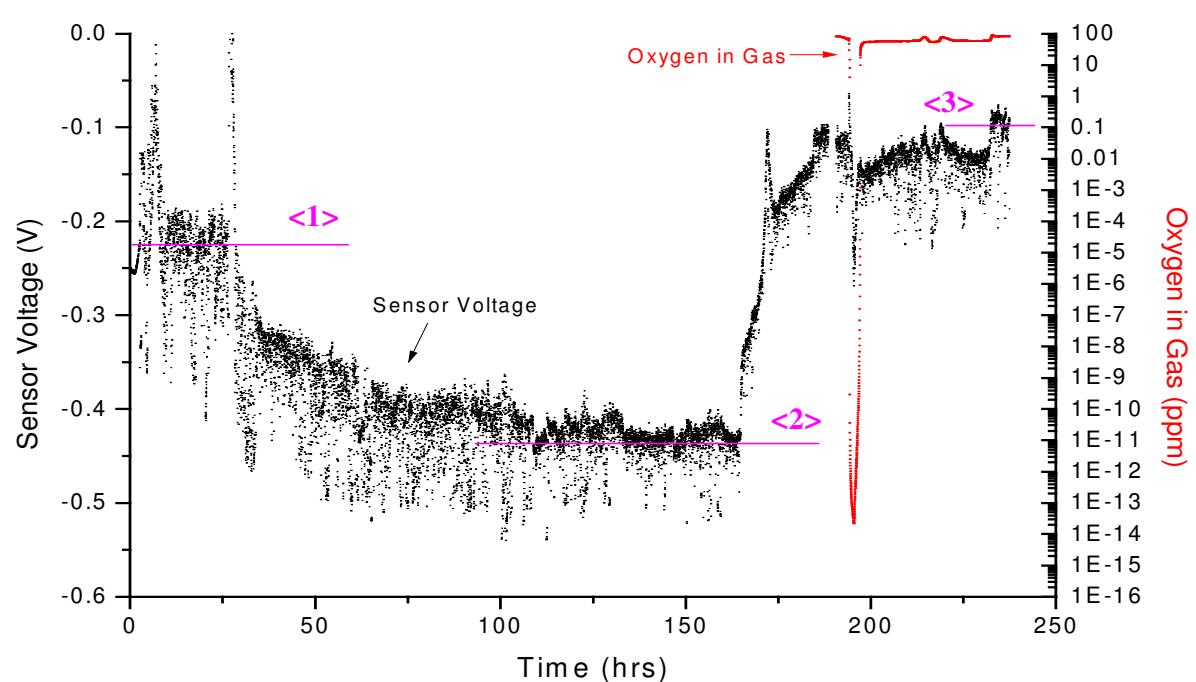

Figure 7. Whole sensor signal voltage history of an YSZ oxygen sensor obtained by controlling oxygen concentration in liquid $\mathrm{LBE}$ at $450{ }^{\circ} \mathrm{C}$.

\section{Conclusions}

Calibration tests for an YSZ oxygen sensor were performed for the measurement of oxygen concentration in liquid LBE at $450{ }^{\circ} \mathrm{C}$. The performance of the sensor in liquid LBE has been verified. From the sensor calibration results, the signal voltage response of the oxygen sensor was very sensitive to the change of oxygen concentration because it decreased or increased quickly when the oxygen concentration was changed. We can observe good calibration results with $\mathrm{Pb} / \mathrm{PbO}$ equilibrium plateau at a maximum saturated oxygen concentration where lead oxide starts to precipitate. However, we can not observe good calibration results with the $\mathrm{Fe} / \mathrm{Fe}_{3} \mathrm{O}_{4}$ equilibrium plateau at a minimum allowable oxygen concentration where steel corrosion sets in. The calibration test results provide a guidance to measure the oxygen concentration in liquid LBE coolant system. The sensor calibration results in this study will be used in the LBE material test loop for measuring and controlling oxygen concentration. We are planning to carry out more sensor calibration tests at several other conditions to accurately measure oxygen concentrations in liquid LBE.

\section{References}

1. G. Heusener and M. Salvatores, in Proc. of the Heavy Liquid Metal Coolants in Nuclear Technology, Obninsk, Rusia. (1998).

2. F. Balbaud-Celerier and A. Terlain, J. Nuc. Mat. 335 (2002) 204.

3. N. Li, J. Nuc. Mat. 300 (2002) 73.

4. T.W. Darling and N. Li, Proc. AccApp-ADTTA 1, Reno, NV, (2001).

5. J. Fraden, $2^{\text {nd }}$ Ed., Handbook of Modern Sensors: Physics, Designs, and Applications. Woodbury, NY: American Institute Physics Press, (1977).

6. R. Sivaraman, Master Thesis, University of Nevada Las Vegas, USA, (December 2003).

7. J.A. Fernandez, J. Abella, and L. Victori, J. Nuc. Mat. 301 (2002) 47. 
8. A. Seidl and G. Muller, J. Electrochem. Soc. 144 (1997) 3243.

9. J. Konys, H. Muscher, Z. Vob and O. Wedemeyer, J. Nuc. Mat. 296 (2001) 289.

10. G.V. Samson, The Oxide Handbook, $2^{\text {nd }}$ Ed., IFI/Plenum, New York, (1982).

11. G. Muller, G. Schumacher and F. Zimmermann, J. Nuc. Mat. 278 (2000) 85. 